\title{
Measuring smoking-related preoccupation and compulsive drive: evaluation of the obsessive compulsive smoking scale
}

\author{
Brian Hitsman • Biing-Jiun Shen • Ronald A. Cohen • Sandra B. Morissette • \\ David J. Drobes • Bonnie Spring • Kristin Schneider • David E. Evans • \\ Suzy B. Gulliver • Barbara W. Kamholz • Lawrence H. Price • Raymond Niaura
}

Received: 3 March 2010 /Accepted: 2 June 2010 /Published online: 26 June 2010

(C) The Author(s) 2010. This article is published with open access at Springerlink.com

\begin{abstract}
Rationale Tobacco use for many people is compulsive in nature. Compelling theories of how smoking becomes compulsive exist but are largely based on extrapolation from neuroscience findings. Research on smokers is impeded, in part, by a lack of instruments that specifically measure compulsive smoking.

Objective This study evaluated the measurement structure and validity of the Obsessive Compulsive Smoking Scale (OCSS), a ten-item questionnaire designed to measure compulsive smoking.

Methods Participants were 239 daily smokers ( $\geq 1$ cigarette/ day), including 142 students at a public university in Chicago and 97 veterans treated at the VA Boston Health-
\end{abstract}

B. Hitsman $(\bowtie) \cdot$ B. Spring

Department of Preventive Medicine, Northwestern University

Feinberg School of Medicine,

680 N. Lake Shore Drive, Suite 1400,

Chicago, IL 60611, USA

e-mail: b-hitsman@northwestern.edu

\section{B.-J. Shen}

Department of Psychology, University of Southern California,

Los Angeles, CA, USA

\section{R. A. Cohen $\cdot$ L. H. Price}

Department of Psychiatry and Human Behavior,

The Warren Alpert Medical School of Brown University,

Providence, RI, USA

S. B. Morissette $\cdot$ S. B. Gulliver

Health Science Center, Texas A\&M College of Medicine

and Central Texas Veterans Healthcare System,

Waco, TX, USA

\section{J. Drobes}

Departments of Oncologic Sciences and Psychology,

Moffitt Cancer Center and University of South Florida,

Tampa, FL, USA care System. The OCSS and questionnaires measuring current and past smoking, cigarette craving, automatic smoking, and nicotine dependence were administered.

Results Factor analysis with maximum likelihood extraction and oblique rotation revealed two correlated underlying factors, interpreted as "Preoccupation with Smoking" and "Compulsive Drive." The measurement structure was consistent across students and veterans, and confirmed in an independent sample of adults $(n=95)$. Veterans exhibited higher OCSS scores (full scale and subscales) than students. Across groups, higher OCSS scores were positively correlated with smoking intensity, craving, and nicotine dependence. OCSS full-scale and compulsive drive scores, but not smoking preoccupation scores, were inversely

\section{K. Schneider}

Department of Medicine,

University of Massachusetts Medical School,

Worcester, MA, USA

D. E. Evans

Moffitt Cancer Center,

Tampa, FL, USA

B. W. Kamholz

Departments of Psychology and Psychiatry,

VA Boston Healthcare System and Boston University,

Boston, MA, USA

\section{R. Niaura}

The Schroeder Institute for Tobacco Research and Policy Studies, American Legacy Foundation,

Washington, DC, USA 
correlated with past month smoking reduction and minutes since last cigarette.

Conclusions The OCSS is a valid and reliable inventory for measuring the degree to which daily smokers are preoccupied with smoking and engage in compulsive tobacco use, and may be useful for advancing understanding of core smoking phenotypes or for tailoring cessation therapies.

Keywords Tobacco use · Addiction - Smoking preoccupation $\cdot$ Compulsive smoking $\cdot$ Craving . Psychometrics - Obsessive compulsive smoking scale . College students $\cdot$ Adults

\section{Introduction}

Drug use is increasingly recognized as being compulsive in nature (Chassin et al. 2007; Everitt and Robbins 2005; Kalivas and Volkow 2005; Koob and Le Moal 2008; Tiffany and Carter 1998; Volkow and Fowler 2000). In the case of tobacco use and dependence, many smokers devote significant time and money to smoke cigarettes. Smokers express both desire to stop smoking and great difficulty doing so, and persist in smoking despite knowledge of its significant adverse health consequences. Moreover, smokers describe the nature of their tobacco use and craving as persistent and intrusive, and often anticipate coping with craving as the most difficult part of smoking cessation (Orleans et al. 1991).

The developmental course and neurobehavioral mechanisms by which tobacco use becomes compulsive remain poorly understood, yet both have important implications for treatment and prevention. Compelling theories have been advanced over the last decade, but these are largely based on extrapolation from basic neuroscience findings (Everitt and Robbins 2005; Robinson and Berridge 2003; Volkow and Fowler 2000). Abnormalities in neural systems that mediate inhibitory control of behavior (e.g., orbital frontal and limbic regions) have led to the conceptualization of drug addiction as a "disease of compulsion and drive" (Volkow and Fowler 2000). Behavioral models emphasize the contributions of primary (positive and negative) and secondary reinforcement processes and can be conceptualized within neural models to explain the development of compulsive drug seeking and use (Everitt and Robbins 2005; Weiss 2005). For example, Everitt and Robbins (2005) highlight the role of conditioning and learning processes that result in drug use behavior that progresses from "action to habit to compulsion."

Research on smokers is impeded, in part, due to the lack of published instruments that specifically measure compulsive smoking. Evidence of the dimensionality of the Fagerström Test of Nicotine Dependence (Breteler et al.
2004), as well as multidimensional measures of tobacco dependence, such as the 19-item Nicotine Dependence Syndrome Scale (NDSS; Shiffman et al. 2004) and the 68item Wisconsin Inventory of Smoking Dependence Motives (WISDM) (Piper et al. 2004), underscore the potential critical importance of compulsive use in understanding vulnerability to regular smoking and nicotine dependence. Based on almost 1,500 smokers pooled from three smoking cessation trials, Piper and colleagues (2008) found that four of the 13 WISDM subscales, craving (four items), tolerance (five items), automaticity (five items), and loss of control (four items), were the strongest predictors of key features of dependence and of relapse.

To our knowledge, only the Automatic Smoking Questionnaire (ASQ, unpublished) was specifically developed to assess an aspect of compulsive smoking behavior (Burton et al. 1990). The ASQ is based on Tiffany's cognitive model of addictive behavior (Tiffany 1990), which asserts that over the course of repeated selfadministration, drug use becomes automatic. As with the two subscales from the WISDM (i.e., loss of control and automaticity), the ASQ measures loss of control over smoking behavior that occurs in the absence of awareness, but it does not capture other potentially important features of compulsive smoking. Despite the great importance and need for a focused assessment of compulsive smoking, a validated, reliable, and easy to administer measurement is still lacking.

The aim of this study was to evaluate the psychometric properties of the ten-item Obsessive Compulsive Smoking Scale (OCSS). The OCSS was adapted from the Obsessive Compulsive Drinking Scale (OCDS), a valid and reliable scale widely used by clinicians and researchers in the alcohol field. (Anton 2000). The OCSS differs from multidimensional measures of tobacco dependence, such as the WISDM, in that it provides a focused measure of excessive preoccupation with smoking (e.g., amount of time per day occupied by smoking-related thoughts) and compulsive smoking behavior (e.g., degree of perceived control over urges and effort to resist smoking). By comprehensively assessing these and other cognitive, emotional, and behavioral features of compulsive smoking, the OCSS may provide unique information that is lacking in the ASQ.

Our approach to instrument evaluation was as follows: the OCSS and other smoking-related measures were administered to two different samples of smokers who reported at least one cigarette per day: college students and veterans receiving outpatient medical treatment. These groups were targeted to evaluate whether the psychometric properties of the OCSS would be consistent across daily smokers representing opposite ends of the tobacco addiction continuum. To determine the measurement structure of 
the OCSS and its underlying dimensions, we conducted exploratory factor analysis (EFA). We then examined the internal consistency reliability using Cronbach's alpha. To validate the structure derived from the EFA, we performed a confirmatory factor analysis (CFA) of data from an independent sample of adult smokers. Finally, concurrent validity was evaluated by testing associations between the OCSS and various smoking characteristics, including automatic smoking as measured by ASQ.

\section{Method}

\section{Participants}

Participants were 239 smokers (176 men) ages 18-55. All smoked daily, as defined by self-report of at least one cigarette per day. Fifty-nine percent of the sample $(n=142)$ comprised students at a large public university in Chicago, Illinois, who received course credit for their participation. We also recruited 97 veterans receiving healthcare at the VA Boston Healthcare System. They were paid $\$ 10$ for their participation. Exclusion criteria included interest in quitting smoking, as defined by self-report greater than 5 on a 10-point scale of readiness to quit $(10=$ strong desire; Biener and Abrams 1991), or current involvement in smoking cessation treatment.

\section{Measures}

Obsessive Compulsive Smoking Scale The OCSS is a 10item self-report questionnaire designed to measure compulsive smoking (see Appendix). It is based upon the widely used Obsessive Compulsive Drinking Scale (Anton 2000; Anton et al. 1995), which was derived from the Yale-Brown Obsessive Compulsive Scale for the assessment of obsessive compulsive disorder (Goodman et al. 1989a, b).

The structure and format of the 14-item OCDS was retained in the OCSS. To adapt the scale to cigarette smoking, the words "alcohol" and "drinking" were replaced with "cigarettes" and "smoking." We chose not to include the four items that would have measured consumption and the consequential impact of tobacco use. Two items would have measured frequency of smoking (cigarettes per day, days per week in which at least one cigarette was smoked) and the other two would have measured the direct consequences of smoking on social and/or occupational functioning. They were excluded from the scale because they did not represent the constructs of interest, but rather they seemed more appropriately construed as behavioral outcomes resulting from the theoretical constructs.
Participants responded to each of the ten OCSS items by choosing from five options with corresponding scores from 0 to 4 indicating the degree to which they endorsed the item. "Obsessive" items were the following: time per day occupied by thoughts, frequency of thoughts per day, interference of thoughts with social and work activities, level of distress associated with thoughts, effort to resist thoughts, and control over thoughts. "Compulsive" items were level of distress if prevented from smoking, effort to resist smoking, strength of urges, and control over smoking.

Demographics, smoking, and health history Participants completed a questionnaire that requested information on age, gender, education, current and past smoking, and current use of psychotropic medication. Medication status was defined as self-report of "no" or "yes" plus verification that the participant's listed medication(s) was psychotropic in nature. Use of psychotropic medication was considered to reflect a possible history of psychiatric disorder. Retrospective report of seriousness of problems with craving during past quit attempts was made using a fivepoint scale ranging from "not at all serious" to "extremely serious." Using 1998 data compiled by the US Federal Trade Commission, nicotine content (in milligram) was recorded based on preferred cigarette brand.

Automatic smoking behavior Derived from Tiffany's cognitive theory of drug use behavior (Tiffany 1990), the ASQ consists of 41 items that comprise five factors, with internal consistency estimates ranging from 0.68 to 0.89 (Burton et al. 1990). They include stimulus bound (smoking routinely in the presence of certain stimuli), autonomous smoking (the sense of an absence of conscious control over smoking), dual task (ability to smoke while engaging in other activities), stereotyped smoking (stereotyped pattern of smoking), and memory failure (awareness of smoking without recalling its initiation). Only veterans were administered the ASQ.

Subjective cigarette craving Subjective craving was measured using the Questionnaire of Smoking Urges-Brief version (QSU-Brief; Cox et al. 2001). The QSU-Brief is a widely used scale that yields a measure of urge to smoke. The full-scale score was computed by summing the 10 items. Higher scores suggest greater urges to smoke.

Nicotine dependence The six-item Fagerström Test for Nicotine Dependence (FTND) was administered to measure nicotine dependence (Heatherton et al. 1991). A high degree of dependence is indicated by the following behaviors: smoking first cigarette of the day soon after awakening, smoking more frequently during first hours of 
waking, difficulty refraining from smoking in places where smoking is not permitted, first cigarette of the day is most satisfying, heavy daily smoking, and smoking despite illness. Fagerstrom et al. (1992) recommend the following classification of scores: very low or no dependence (0-2), low (3-4), medium (5), and high dependence $(\geq 6)$. The FTND has adequate reliability and validity (Buckley et al. 2005)

\section{Procedure}

After eligibility screening, participants completed the OCSS and other smoking-related questionnaires. Among the veteran sample, a positive self-report of smoking was confirmed by expired carbon monoxide levels $(\mathrm{CO}) \geq 8$ parts per million (ppm; SRNT Subcommittee on Biochemical Verification 2002). Among the student sample, daily smoking was obtained by self-report only. Daily smoking for both groups was defined as $\geq 1$ cigarette per day. Completion time for the study was about $45 \mathrm{~min}$. The study was approved by the Institutional Review Boards of the University of Illinois at Chicago, VA Boston Healthcare System, and The Miriam Hospital in Providence, Rhode Island.

\section{Psychometric validation plan}

Our primary goals were to: (1) evaluate the psychometric properties of the OCSS and (2) establish its validity by comparing OCSS responses of college students and veteran smokers to their responses on the various smoking measures. Exploratory factor analysis (EFA) was conducted to explore the measurement structure of the OCSS and identify underlying dimensions or subscales. We calculated Cronbach's alpha of the full-scale and subscales to examine their reliability of internal consistencies.

CFA was used to evaluate whether the measurement structure observed in the primary sample could be replicated in an independent sample. The CFA sample comprised 95 smokers (49 men) involved in one of two separate laboratory studies of smoking and cognition conducted at the University of South Florida. In both studies, cognitive testing was completed after completion of the OCSS and some of the self-report measures described above (see Evans et al. 2009 for details on one of the two studies). Participants were required to be 18-55 years old, smoke 15 or more cigarettes per day during the past year, and have expired CO levels $\geq 8 \mathrm{ppm}$. Exclusion criteria included current smoking reduction or attempt to quit smoking. Participants were paid $\$ 30-\$ 50$ depending on the study.
Statistical analysis

Analyses were conducted using SPSS 14.0 for Windows (SPSS Inc). EFA was conducted to explore the underlying measurement structure and potential dimensions of the 10 OCSS items (Comrey and Lee 1992). The maximum likelihood method was used to extract all factors with Eigenvalues greater than 1.00 initially. The maximum likelihood method estimates the population factor loadings by computing the loadings such that they maximize the probability of the observed correlation matrix of the sample. It is considered an advantageous method especially when data are relatively normally distributed as they were in this study (Fabrigar et al. 1999). A scree plot test was used to help determine the final optimal number of factors that best represented the measurement structure of the OCSS. After the extraction stage, factors were rotated to facilitate meaningful interpretation. Because we anticipated the emergence of related yet differentiable content domains, oblique rotation was applied to allow the rotated factors to be correlated. The EFA was first conducted on the student and veteran samples separately to compare whether a similar structure was observed in these two groups and then on the combined sample to inspect and compare whether the observed measurement structure was robust and stable.

To cross-validate the structure observed in the EFA results, we conducted a CFA in the independent sample of smokers. As opposed to the EFA, in which empirical data determine the solution a posteriori, CFA allowed us to impose an a priori model on the data and test how well the hypothesized structure fits the data. The EFA findings provided the rationale and basis for CFA model specifications. Goodness of fit (comparative fit index/CFI) and badness of fit (root mean square error of approximation/ RMSEA) indices were computed. The CFI compares the independent model with the fully saturated model, ranging from zero to 1.0, with 1.0 considered a perfect fit. A CFI of 0.90 indicates an adequate fit and a RMSEA above 0.10 a poor fit (Kline 2005). Chi-square $\left(\chi^{2}\right)$ of the model was also reported. The $\chi^{2}$ difference test was used to evaluate whether the hypothesized two-factor model yielded a significantly better fit than the single factor model. The factors were permitted to correlate.

As tests of concurrent validity, we examined the associations between OCSS scores (full scale and EFAderived subscales) and variables related to cigarette craving, nicotine dependence, smoking behavior, and smoking history. Given the expected difference between veterans and students in smoking history, intensity, and degree of dependence, we evaluated the hypothesis that veterans would score higher on the OCSS than the students. In addition, because adult smokers with co-occurring psycho- 
pathology show greater smoking persistence than nonpsychiatric smokers (see Ziedonis et al. 2008), potentially due in part to greater compulsive smoking, we tested whether veterans taking psychotropic medication (e.g., antidepressants or anti-anxiety medications) would score higher than unmedicated veterans. An alpha level of 0.01 was used for all tests of concurrent validity.

\section{Results}

Sample characteristics

Table 1 presents the demographic and smoking characteristics for students, veterans, and participants in the CFA sample. Comparisons of students and veterans revealed that veterans were older with a greater proportion of men. They also reported an earlier age of smoking initiation, more years smoking, and a greater degree of nicotine dependence (classified as moderately dependent).

\section{Measurement structure of the OCSS}

In the veteran, student, and combined samples, two factors with Eigenvalues $>1$ were extracted. The scree plots showed that the two-factor solution was optimal in representing the underlying dimensions. The factor loadings of all OCSS items on each rotated factor for each of the samples are presented in Table 2. The first factor was represented by items assessing preoccupation with smoking when not smoking (items 1 and 2), interference of this preoccupation with social and work functioning (item 3), distress associated with smoking-related thoughts (item 4), and effort to control or resist such thoughts (items 5 and 6).
Therefore, we named this factor "Preoccupation with Smoking." The second factor was represented by four items: emotional distress if prevented from smoking in the presence of a desire to smoke (item 7), degree of effort to resist smoking (item 8), strength of urge to smoke (item 9), and degree of control over smoking (item 10). Because these items tapped intensity of smoking urge, control over smoking, and associated emotional distress, this factor was named "Compulsive Drive." The correlations between subscales indicated shared variance of $23 \%$ (veterans) to $42 \%$ (full sample).

\section{Confirmatory factor analysis of the OCSS}

Characteristics of the CFA sample also are presented in Table 1. On the basis of the EFA, we specified a model of two correlated latent factors with smoking preoccupation represented by items 1-6 and compulsive drive represented by items $7-10$. We observed particularly strong associations between items 1 and 2 (amount of time occupied by smoking-related thoughts and frequency of thoughts per day), items 1 and 5 (amount of time occupied by smokingrelated thoughts and effort to resist them), and items 3 and 4 (interference of thoughts with social/work functioning and emotional distress associated with them) that could not be represented by the common latent factor, smoking preoccupation We considered these associations to be justified. Consequently, these three parameters were added to estimate the covariances between residual variances of these items and the model was subjected to CFA.

The model produced $\chi^{2}=42.2(\mathrm{df}=31, p>0.05), \mathrm{CFI}=$ 0.97 , and $\mathrm{RMSEA}=0.06\left(\mathrm{CI}_{90}=0.00,0.10\right)$, with all demonstrating an adequate fit between the proposed measurement structure and the empirical data. The loadings

Table 1 Demographic and smoking characteristics of college students, veterans, and CFA sample

\begin{tabular}{llll}
\hline Participant characteristics & Students $(n=142)$ & Veterans $(n=97)$ & CFA sample $(n=95)$ \\
\hline Age (in years) ${ }^{* *}$ & $19.5(1.7)$ & $46.7(4.9)$ & $31.9(10.7)$ \\
Gender $\left(\%\right.$ male) $^{* *}$ & $58 \%$ & $97 \%$ & $52 \%$ \\
Highest grade completed & $12.8(1.0)$ & $12.6(1.6)$ & $13.3(2.9)$ \\
Age when first smoked & $14.9(2.2)$ & $13.5(4.0)$ & $14.4(4.7)$ \\
Age of daily smoking & $17.1(1.6)$ & $17.2(5.9)$ & $17.6(5.9)$ \\
Cigarettes/day since daily smoking $^{* *}$ & $6.6(5.4)$ & $20.5(9.7)$ & $22.9(7.4)^{\mathrm{a}}$ \\
FTND (possible range 0-10) & $1.7(2.0)$ & $5.7(2.0)$ & $5.1(2.2)$ \\
Years smoking $^{* *}$ & $3.4(2.0)$ & $30.0(9.0)$ & $13.7(9.8)$ \\
Prior quit attempts $(>12 \mathrm{~h})$ & $5.0(7.1)$ & $7.1(13.0)$ & $2.6(3.2)^{\mathrm{b}}$ \\
\hline
\end{tabular}

Chi-square comparisons for gender; $t$ test comparisons for all other variables

${ }^{\text {a }}$ Assessed in the CFA sample as cigarettes smoked per day currently

${ }^{\mathrm{b}}$ Assessed in the CFA sample as "Have you tried to quit smoking? If yes, how many times?"

${ }^{*} p<0.01$, comparison between students and veterans

${ }^{* *} p<0.001$, comparison between students and veterans 
Table 2 Results of the exploratory factor analysis of the OCSS with maximum likelihood extraction and oblique rotation: factor loadings

\begin{tabular}{|c|c|c|c|c|c|c|}
\hline \multirow[t]{2}{*}{ OCSS Item } & \multicolumn{2}{|c|}{ Veterans $(n=97)$} & \multicolumn{2}{|c|}{ Students $(n=142)$} & \multicolumn{2}{|c|}{ Full sample $(n=239)$} \\
\hline & $\begin{array}{l}\text { Preoccupation } \\
\text { with smoking }\end{array}$ & $\begin{array}{l}\text { Compulsive } \\
\text { drive }\end{array}$ & $\begin{array}{l}\text { Preoccupation } \\
\text { with smoking }\end{array}$ & $\begin{array}{l}\text { Compulsive } \\
\text { drive }\end{array}$ & $\begin{array}{l}\text { Preoccupation } \\
\text { with smoking }\end{array}$ & $\begin{array}{l}\text { Compulsive } \\
\text { drive }\end{array}$ \\
\hline $\begin{array}{l}\text { 1. Amount of time per day occupied by } \\
\text { thoughts }\end{array}$ & 0.68 & 0.51 & 0.58 & 0.24 & 0.66 & 0.40 \\
\hline 2. Frequency of thoughts per day & 0.61 & 0.46 & 0.63 & 0.32 & 0.66 & 0.42 \\
\hline 3. Interference of thoughts (social/work) & 0.74 & 0.53 & 0.60 & 0.32 & 0.74 & 0.51 \\
\hline 4. Emotional distress associated with thoughts & 0.74 & 0.63 & 0.71 & 0.39 & 0.79 & 0.58 \\
\hline 5. Effort to resist thoughts & 0.77 & 0.19 & 0.71 & 0.48 & 0.72 & 0.41 \\
\hline 6. Control over thoughts & 0.90 & 0.40 & 0.77 & 0.57 & 0.84 & 0.56 \\
\hline $\begin{array}{l}\text { 7. Emotional distress if prevented from } \\
\text { smoking }\end{array}$ & 0.41 & 0.73 & 0.38 & 0.70 & 0.50 & 0.75 \\
\hline 8. Effort to resist cigarette smoking & 0.20 & 0.46 & 0.42 & 0.74 & 0.40 & 0.67 \\
\hline 9. Strength of urge to smoke & 0.37 & 0.80 & 0.45 & 0.76 & 0.54 & 0.84 \\
\hline 10. Control over cigarette smoking & 0.43 & 0.76 & 0.39 & 0.81 & 0.54 & 0.83 \\
\hline Total variance explained & \multicolumn{2}{|l|}{$56 \%$} & \multicolumn{2}{|l|}{$50 \%$} & \multicolumn{2}{|l|}{$65 \%$} \\
\hline Correlation between subscales & \multicolumn{2}{|l|}{0.48} & \multicolumn{2}{|l|}{0.53} & \multicolumn{2}{|l|}{0.64} \\
\hline
\end{tabular}

(standardized path coefficients) of items $1-6$ of smoking preoccupation were $0.67,0.72,0.60,0.67,0.75$, and 0.81 ; loadings of items $7-10$ of compulsive drive were 0.66 , $0.64,0.68$, and 0.75 . The correlation between the two latent factors was 0.73 . We also tested a single-factor model with the same modifications. The single-factor model $\left(\chi^{2}=66.9\right.$, $\mathrm{df}=32, p<0.001)$ had a marginally adequate fit as measured by CFI (0.91) and a poor fit as measured by RMSEA $(0.11$, $\left.\mathrm{CI}_{90}=0.07,0.15\right)$. However, the single-factor model performed significantly more poorly than the two-factor model $\left(\chi_{\text {diff }}^{2}=24.7, \mathrm{df}=1, p<0.001\right)$. In short, the CFA results supported the two-factor structure observed in our exploratory analysis.

\section{Internal consistency reliability}

Cronbach's $\alpha$ was calculated to assess the internal consistency of the OCSS and the two subscales. The Cronbach's $\alpha$ was 0.88 for veterans, 0.86 for students, and 0.89 for the full scale indicating excellent reliability of internal consistency. Each subscale also showed high levels of internal consistency of content, with smoking preoccupation reaching $\alpha$ of $0.87(0.88$ for veterans, 0.82 for students) and compulsive drive having $\alpha$ of 0.85 ( 0.79 for veterans, 0.83 for students).

\section{Concurrent validity}

Table 3 displays correlations between OCSS scores (full scale, smoking preoccupation, compulsive drive) and measures of craving, automatic smoking, nicotine dependence, smoking history, and recent smoking. The full-scale OCSS score was obtained by summing the 10 items. Subscale scores were obtained by summing items within each subscale. Higher scores indicate higher levels of compulsive smoking.

OCSS full scale and subscale scores were positively correlated with level of craving and seriousness of problems with craving during past quit attempts. Positive correlations were observed for automatic smoking behavior, with three exceptions. OCSS full-scale scores was unrelated to stereotyped smoking, smoking preoccupation was unrelated to stereotyped and stimulus bound smoking, and compulsive drive was unrelated to dual task smoking. Several indices of nicotine dependence, including the nicotine content of participants' preferred cigarette $(M=1.0 \mathrm{mg}, \mathrm{SD}=0.25)$, cigarettes per day since onset of daily smoking, and degree of dependence, were positively correlated with OCSS scores. With respect to smoking history, OCSS scores were positively correlated with total years of smoking. Scores were unrelated to age of daily smoking, number of past quit attempts greater than $12 \mathrm{~h}$, or longest period of abstinence, although the latter set of correlations was significant among veterans (full scale $0.28, p<0.001$; smoking preoccupation 0.22 , $p=0.012$; compulsive drive $0.27, p=0.002$ ).

Several cigarette consumption indices were used to evaluate whether OCSS scores were sensitive to recent smoking behavior. Higher OCSS full scale and compulsive drive scores, but not smoking preoccupation scores, were negatively correlated with past month reduction in cigarettes per day ( $n=114$ reported a reduction). Positive correlations were found between the OCSS scores and cigarettes per day over the past week and cigarettes smoked on the day of 
Table 3 Pearson product moment correlations between OCSS scores (full scale, preoccupation with smoking, compulsive drive) and scores on other smoking-related measures

${ }^{*} p<0.01,{ }^{* *} p<0.001$

\begin{tabular}{|c|c|c|c|}
\hline Variable & Full scale & Preoccupation with smoking & Compulsive drive \\
\hline \multicolumn{4}{|l|}{ Subjective craving } \\
\hline QSU-Brief & $0.49 * *$ & $0.42 * *$ & $0.46^{* *}$ \\
\hline Severity during past quit attempts & $0.51 * *$ & $0.36^{* *}$ & $0.55 * *$ \\
\hline \multicolumn{4}{|l|}{ Automatic smoking } \\
\hline Full scale & $0.46^{* *}$ & $0.37 * *$ & $0.46^{* *}$ \\
\hline Stimulus bound & $0.36^{* *}$ & 0.25 & $0.42 * *$ \\
\hline Autonomous smoking & $0.39 * *$ & $0.30 *$ & $0.40 * *$ \\
\hline Dual task & $0.30 *$ & $0.36^{* *}$ & 0.10 \\
\hline Stereotyped smoking & 0.25 & 0.14 & $0.33 *$ \\
\hline Memory failure & $0.44 * *$ & $0.37 * *$ & $0.40 * *$ \\
\hline \multicolumn{4}{|l|}{ Severity of nicotine dependence } \\
\hline FTND & $0.61 * *$ & $0.46^{* *}$ & $0.65 * *$ \\
\hline Nicotine content of preferred cigarette & $0.24 * *$ & $0.24 * *$ & $0.19 *$ \\
\hline Cigarettes/day since daily smoking & $0.48^{*}$ & $0.34 *$ & $0.53 *$ \\
\hline \multicolumn{4}{|l|}{ Smoking history } \\
\hline Years smoking & $0.42 *$ & $0.33^{*}$ & $0.42 *$ \\
\hline Age of onset of daily smoking & -0.02 & 0.01 & -0.05 \\
\hline Past quit attempts ( $\geq 12$ hours) & -0.03 & -0.02 & 0.04 \\
\hline Longest period of abstinence & -0.09 & -0.10 & -0.05 \\
\hline \multicolumn{4}{|l|}{ Recent smoking behavior } \\
\hline Reduced smoking past month & $-0.16^{*}$ & -0.08 & $-0.23 * *$ \\
\hline Cigarettes per day past week & $0.59 *$ & $0.41 *$ & $0.67 *$ \\
\hline Cigarettes smoked on day of study & $0.57^{*}$ & $0.47^{*}$ & $0.54 *$ \\
\hline Minutes since last cigarette & $-0.19^{*}$ & -0.11 & $-0.24 * *$ \\
\hline
\end{tabular}

testing. Minutes since last cigarette, reported by participants immediately prior to completion of the OCSS, were negatively correlated with full scale and Compulsive drive scores. Smoking preoccupation was unrelated to minutes since last cigarette. The mean duration was $131.9(\mathrm{SD}=305.7) \mathrm{min}$.

Full scale and subscale differences

Table 4 displays the mean scores for students, veterans, and the CFA sample. One-way ANOVAs comparing the three groups revealed significant differences on all OCSS scales: full scale $[F(2,329)=39.7, p<0.001]$, smoking preoccupation $[F(2,329)=20.3, p<0.001]$ and compulsive drive $[F(2,329)=$ $49.1, p<0.001]$. Pairwise comparisons conducted using the Scheffé test showed that veterans and adults in CFA sample had higher scores than students. Within veterans, $t$ tests comparing medicated and unmedicated participants showed that those taking psychotropic medication exhibited higher full scale $[t(92)=2.4, p=0.01]$, smoking preoccupation $[t(92)=2.0, p=$ $0.04]$, and compulsive drive scores $[t(92)=2.2, p=0.02]$.

Table 4 OCSS full scale and subscale scores for college students, veterans, and CFA sample

\begin{tabular}{lrrrr}
\hline Scale score & $\begin{array}{l}\text { Students } \\
(n=142)\end{array}$ & $\begin{array}{l}\text { Veterans } \\
(n=94)\end{array}$ & $\begin{array}{l}\text { Non-medicated veterans } \\
(n=46)\end{array}$ & $\begin{array}{l}\text { Medicated veterans } \\
(n=48)\end{array}$ \\
\hline Full scale & $10.2(6.0)^{\mathrm{a}}$ & $16.6(7.3)$ & $14.7(6.4)$ & $\begin{array}{l}\text { CFA sample } \\
(n=97)\end{array}$ \\
Preoccupation with smoking & $5.3(3.7)^{\mathrm{a}}$ & $8.5(5.2)$ & $7.4(4.6)$ & $\begin{array}{r}18.2(7.9)^{\mathrm{b}} \\
9.5(5.6)^{\mathrm{b}}\end{array}$ \\
Compulsive drive & $4.9(3.1)^{\mathrm{a}}$ & $8.0(3.2)$ & $7.3(2.9)$ & $8.7\left(3.9(3.3)^{\mathrm{b}}\right.$ \\
\hline
\end{tabular}

Possible range of OCSS scores: full scale 0-40, preoccupation with smoking (6 items) $0-24$, compulsive drive (4 items) $0-16$. Three veterans were missing data on psychiatric medication status.

${ }^{\text {a }}$ Students significantly lower than veterans or CFA sample $(p<0.05)$

${ }^{\mathrm{b}}$ Veterans reporting use of psychotropic medication significantly higher than those not taking medication $(p<0.05)$ 


\section{Discussion}

The OCSS comprises two reliable and valid correlated factors that measure cognitive, emotional, and behavioral features of compulsive smoking. "Preoccupation with Smoking" was characterized by amount of time occupied by smoking-related thoughts when not smoking, frequency of thoughts when not smoking, degree of interference of thoughts with work and social functioning, level of emotional distress associated with thoughts, and degree of effort to resist and to control them. "Compulsive Drive" was characterized by general intensity of smoking-related urges, level of emotional distress if prevented from smoking, degree of effort to resist smoking, and degree of control over smoking. This measurement structure was stable across college students and veterans, who differed substantially on cigarettes smoked per day, degree of nicotine dependence, and length of smoking history, and confirmed in an independent sample of adult heavy smokers. The OCSS and its subscales also demonstrated high internal consistency. The two subscales had only $23-42 \%$ of variance in common. Concurrent validity was supported by the finding that higher OCSS scores were associated with greater subjective craving, several aspects of nicotine dependence, and intensity of recent smoking.

The observed associations between OCSS scores and other widely used smoking measures demonstrate that the OCSS is measuring constructs that are important to tobacco use and dependence. Two scales in particular shared substantial yet only partial variance with the OCSS. The FTND shared $37 \%$ of its variance with the OCSS while the QSU-Brief shared $24 \%$ of its variance. Thus, the OCSS appears to provide substantial unique information beyond what is measured by either the FTND or QSU-Brief, and indicates that the OCSS is tapping into aspects of smoking behavior that are different than either subjective craving or severity of nicotine dependence.

In contrast to our conceptualization of the OCSS, the OCDS has largely been viewed as a measure of craving. In cross-sectional analyses of the 14-item OCDS, higher scores have been associated with higher levels of alcohol craving and consumption as well as with abstinence status during treatment (alcohol slips and relapse) (Anton et al. 1996). In prospective analyses, OCDS scores have been shown to be sensitive to changes in short-term abstinence status, such as time to first heavy drinking day, and consumption levels (Roberts et al. 1999). A 12-item version that eliminated the two quantity items (drinks per day and drinking days per week), as done with the OCSS, comprised two factors, labeled "obsessions", and "compulsions" (Nakovics et al. 2008). While the OCSS includes some items that appear within traditional tobacco craving indices (e.g., subjective craving, effortful and automatized behavior, associated emotional distress), other items reflect attributes not captured by existing craving measures (e.g., preoccupation with smoking, interference).

The total OCSS score merges smoking preoccupation and compulsive drive factors and provides a measure of the tendency of daily smokers to be characterized by them. Students scored lower than veterans on both subscales; however, the magnitude of the difference was much smaller than would be expected given that these two groups could be considered to represent opposite ends of the tobacco addiction continuum. On average, students reported smoking seven cigarettes per day for 3 years, whereas veterans had smoked 20 cigarettes per day for 30 years. Both groups reported onset of daily smoking around age 17. Among veterans, those who reported taking psychotropic medication scored higher than those who reported no medication. This difference does not appear to be simply a reflection of a greater degree of tobacco dependence among medicated veterans as there was no difference between groups in either cigarettes per day since daily smoking or FTND scores.

Although speculative, higher OCSS scores may reflect a specific smoking phenotype comprised of smokers who, soon after transitioning to daily use, become excessively preoccupied with smoking and develop "pathological wanting" (Robinson and Berridge 2003). Whether smoking-related preoccupation and compulsive behavior represent a single phenotype or separate phenotypes could not be evaluated, and will require comparisons of OCSS scores with neurobehavioral and genetic vulnerability measures.

This study represents the first stage in the development of the OCSS. While our findings support the underlying construct of compulsive smoking, as well as the existence of two distinct factors, whether the OCSS is predictive of vulnerability to tobacco dependence or different trajectories from daily use to dependence to persistence requires further study. An important question to be addressed in the next stage of development is the degree to which the OCSS provides information that is clinically distinct from tobacco craving (e.g., Tobacco Craving Questionnaire; Heishman et al. 2003) or certain subscales of multidimensional tobacco dependence measures (i.e., Automaticity and Loss of Control in the WISDM; Drive to Smoke in the NDSS) or offers advantages beyond them.

Several additional directions may be fruitful to pursue with the OCSS. First, the OCSS could be used in smoking cessation trials to examine response to treatment as a function of pre-treatment scores. Predictive validity would be evidenced by associations between pre-treatment OCSS scores and short- or long-term abstinence, as well as other outcomes such as decline in smoking rate across treatment or timing of smoking lapses or relapses. Second, a profile analysis of the OCSS subscales and multidimensional 
tobacco dependence measures (e.g., relevant subscales from the WISDM or NDSS) could provide data on whether these components co-exist in most smokers or exist as unique smoking phenotypes. Finally, it could be valuable to examine the OCSS in relationship to genetic, biological, and psychological predictors of smoking vulnerability and persistence. In future studies of the OCSS, particularly those focused on predictive validity, we recommend continued consideration of the full scale and subscale scores as their potential utility may be established in research involving different measures (e.g., WISDM or Tobacco Craving Questionnaire) and populations (e.g., smokers with co-occurring psychopathology or certain genetic profiles).

To inform neurobehavioral models of tobacco dependence (e.g., Volkow and Fowler 2000), functional brain imaging studies could evaluate whether OCSS scores are correlated with differences in orbital frontal activation on inhibitory control tasks, such as the Go/No Go Task (Garavan et al. 1999), or other regions hypothesized to mediate compulsive tobacco use. Neurotransmitter challenges such as either acute tryptophan depletion or tyrosine/ phenylalanine depletion (Hitsman et al. 2007, 2008) could be used, either alone or in combination with neuroimaging techniques, to evaluate the degree to which acute changes in neurotransmission result in changes in smoking-related preoccupation or compulsive behavior. Importantly, the utility of any future research on mediating neurobehavioral mechanisms will depend upon the successful comprehensive validation of the OCSS.

In summary, results of this study indicate that the OCSS measures unique and potentially important aspects of tobacco dependence. The OCSS is brief and easy to administer and for smokers to complete and therefore should be amenable to clinical use and to research applications. Additional studies are needed to first establish its clinical utility and then to evaluate the extent to which it may inform neurobehavioral models of tobacco use and dependence.

Acknowledgments The authors thank Donna Delaney, Katherine Gechter, Malaina Smith, and Chelsea Wogsland for their assistance with recruitment, testing, and database construction.

Funding and disclosures This study was funded by a Mentored Clinical Scientist Research Career Development Award (K08 DA017145) to Dr. Brian Hitsman. Additional support was provided by a Transdisciplinary Tobacco Use Research Center Grant P50 CA084719 to Dr. Raymond Niaura and Mentored Patient-Oriented Research Career Development Awards to Dr. Sandra B. Morissette (K23 DA016376) and Dr. Barbara W. Kamholz (K23 DA016138).

Dr. Hitsman has consulted for Pinney Associates, subcontracted by GlaxoSmithKline, and Pfizer. Dr. Spring has consulted for Proteus. Dr. Price has received research contacts from Sepracor, UCB Pharma, and Pfizer, speaker's bureau honoraria from Jazz Pharmaceuticals, and has consulted for Gerson Lehrman, Wiley, and Springer. Dr. Niaura has consulted for Pfizer, Sanofi Aventis, GlaxoSmithKline, Novartis, and Orexigen Therapeutics. None of the other co-authors have competing interests to report.

Open Access This article is distributed under the terms of the Creative Commons Attribution Noncommercial License which permits any noncommercial use, distribution, and reproduction in any medium, provided the original author(s) and source are credited.

\section{Appendix}

Obsessive Compulsive Smoking Scale

Directions: The questions below ask you about your smoking and your attempts to control your smoking. Please circle the number next to the statement that best applies to you.

1. How much of your time when you're not smoking is occupied by ideas, thoughts, impulses, images related to smoking?

0 None

1 Less than 1 hour a day

2 1-3 hours a day

3 4-8 hours a day

4 Greater than 8 hours a day

2. How frequently do these thoughts occur?

0 Never

1 No more than 8 times a day

2 More than 8 times a day, but most hours of the day are free of those thoughts

3 More than 8 times a day and during most hours of the day

4 Thoughts are too numerous to count, and an hour rarely passes without several such thoughts occurring.

3. How much do these ideas, thoughts, impulses, or images related to smoking interfere with your social or work functioning? Is there anything you don't or can't do because of them? [If you are not currently working, how much of your performance would be affected if you were working?]

0 Thoughts of smoking never interfere; I can function normally.

1 Thoughts of smoking slightly interfere with my social or work activities, but my overall performance is not impaired.

2 Thoughts of smoking definitely interfere with my social or work performance, but I can still manage.

3 Thoughts of smoking cause substantial impairment in my social or work performance.

4 Thoughts of smoking interfere completely with my social or work performance. 
4. How much distress or disturbance do these ideas, thoughts, impulses, or images related to smoking cause you when you're not smoking?

\section{None}

1 Mild, infrequent, and not too disturbing

2 Moderate, frequent, and disturbing, but still manageable

3 Severe, very frequent, and very disturbing

4 Extreme, nearly constant, and disabling distress

5. How much of an effort do you make to resist these thoughts or try to disregard or turn your attention away from these thoughts as they enter your mind when you're not smoking? [Please rate your efforts made to resist these thoughts, not your success or failure in actually controlling them.]

0 My thoughts are so minimal, I don't need to actively resist. If I have thoughts, I make an effort to always resist.

1 I try to resist most of the time.

2 I make some effort to resist.

3 I give in to all such thoughts without attempting to control them, but I do so with some reluctance.

4 I completely and willingly give in to all such thoughts.

6. How successful are you in stopping or diverting these thoughts when you're not smoking?

0 I am completely successful in stopping or diverting such thoughts.

1 I am usually able to stop or divert such thoughts with some effort and concentration.

2 I am sometimes able to stop or divert such thoughts.

3 I am rarely successful in stopping such thoughts and can only divert such thoughts with difficulty.

4 I am rarely able to divert such thoughts even momentarily.

7. If you were prevented from smoking when you desired a cigarette, how anxious or upset would you become?

0 I would not experience any anxiety or irritation.

1 I would become only slightly anxious or irritated.

2 The anxiety or irritation would mount, but remain manageable.

3 I would experience a prominent and very disturbing increase in anxiety or irritation.

4 I would experience incapacitating anxiety or irritation.

8. How much of an effort do you make to resist smoking? [Only rate your effort to resist, not your success or failure in actually controlling smoking.]

0 My smoking is so minimal, I don't need to actively resist. If I smoke, I make an effort to always resist.
1 I try to resist most of the time.

2 I make some effort to resist.

3 I give in to almost all smoking without attempting to control it, but I do so with some reluctance.

4 I completely and willingly give in to all smoking.

9. In general, how strong is your urge to smoke cigarettes?

0 No urge

1 Some urge to smoke

2 Strong urge to smoke

3 Very strong urge to smoke

4 The urge to smoke is completely involuntary and overpowering.

10. In general, how much control do you have over smoking?

0 I have complete control.

1 I am usually able to exercise voluntary control over it.

2 I can control it only with difficulty.

3 I must smoke and can only delay smoking with difficulty.

4 I am rarely able to delay smoking even momentarily.

\section{References}

Anton RF (2000) Obsessive-compulsive aspects of craving: development of the Obsessive Compulsive Drinking Scale. Addiction 95 (Suppl 2):S211-S217

Anton RF, Moak DH, Latham P (1995) The Obsessive Compulsive Drinking Scale: a self-rated instrument for the quantification of thoughts about alcohol and drinking behavior. Alcohol Clin Exp Res 19:92-99

Anton RF, Moak DH, Latham P (1996) The Obsessive Compulsive Drinking Scale (OCDS): a new method for assessing outcome in alcoholism treatment studies. Archives of General Psychiatry 53:225-231

Biener L, Abrams DB (1991) The Contemplation Ladder: validation of a measure of readiness to consider smoking cessation. Health Psychol 10:360-365

Breteler MH, Hilberink SR, Zeeman G, Lammers SM (2004) Compulsive smoking: the development of a Rasch homogeneous scale of nicotine dependence. Addict Behav 29:199-205

Buckley TC, Mozley SL, Holohan DR, Walsh K, Beckham JC, Kassel JD (2005) A psychometric evaluation of the Fagerstrom Test for Nicotine Dependence in PTSD smokers. Addict Behav 30:1029-1033

Burton SM, Drobes DJ, Tiffany ST (1990, May) A preliminary evaluation of self-reported automatic components in smoking behavior. Annual Meeting of the Midwestern Psychological Association, Chicago, IL

Chassin L, Presson CC, Rose J, Sherman SJ (2007) What is addiction? Age-related differences in the meaning of addiction. Drug Alcohol Depend 87:30-38

Comrey AL, Lee HB (1992) A first course in factor analysis, 2nd edn. Lawrence Erlbaum Associates, Hillsdale

Cox LS, Tiffany ST, Christen AG (2001) Evaluation of the brief questionnaire of smoking urges (QSU-brief) in laboratory and clinical settings. Nicotine Tob Res 3:7-16 
Evans DE, Park JY, Maxfield N, Drobes DJ (2009) Neurocognitive variation in smoking behavior and withdrawal: genetic and affective moderators. Genes Brain Behav 8:86-96

Everitt BJ, Robbins TW (2005) Neural systems of reinforcement for drug addiction: from actions to habits to compulsion. Nat Neurosci 8:1481-1489

Fabrigar LR, Wegener DT, MacCallum RC, Strahan EJ (1999) Evaluating the use of exploratory factor analysis in psychological research. Psychol Methods 4:272-299

Fagerstrom KO, Heatherton TF, Kozlowski LT (1992) Nicotine addiction and its assessment. Ear Nose Throat J 69:763767

Garavan H, Ross TJ, Stein EA (1999) Right hemispheric dominance of inhibitory control: an event-related functional MRI study. Proc Natl Acad Sci USA 96:8301-8306

Goodman WK, Price LH, Rasmussen SA, Mazure C, Fleischmann RL, Hill CL et al (1989a) The yale-brown obsessive compulsive scale. I. Development, use, and reliability. Arch Gen Psychiatry 46:1006-1011

Goodman WK, Price LH, Rasmussen SA, Mazure C, Delgado P, Heninger GR et al (1989b) The yale-brown obsessive compulsive scale. II. Validity. Arch Gen Psychiatry 46:1012-1016

Heatherton TF, Kozlowski LT, Frecker RC, Fagerstrom KO (1991) The Fagerstrom test for nicotine dependence: a revision of the Fagerstrom tolerance questionnaire. Br J Addict 86:11191127

Heishman SJ, Singleton EG, Moolchan ET (2003) Tobacco craving questionnaire: reliability and validity of a new multifactorial instrument. Nicotine Tob Res 5:645-654

Hitsman B, Spring B, Pingitore R, Munafo M, Hedeker D (2007) Effect of tryptophan depletion on the attentional salience of smoking cues. Psychopharmacology 192:317-324

Hitsman B, MacKillop J, Lingford-Hughes A, Williams TM, Ahmad F, Adams S et al (2008) Effects of acute tyrosine/phenylalanine depletion on the selective processing of smoking-related cues and the relative value of cigarettes in smokers. Psychopharmacology 196:611-621

Kalivas PW, Volkow ND (2005) The neural basis of addiction: a pathology of motivation and choice. Am J Psychiatry 162:1403-1413

Kline RB (2005) Principles and practice of structured equation modeling, 2nd edn. Guilford, New York
Koob GF, Le Moal M (2008) Addiction and the brain antireward system. Annu Rev Psychol 59:29-53

Nakovics H, Diehl A, Croissant B, Mann K (2008) Modifications of the Obsessive Compulsive Drinking Scale (OCDS-G) for use in longitudinal studies. Addict Behav 33:1276-1281

Orleans CT, Rimer BK, Cristinzio S, Keintz MK, Fleisher L (1991) A national survey of older smokers: treatment needs of a growing population. Health Psychol 10:343-351

Piper ME, Piasecki TM, Federman EB, Bolt DM, Smith SS, Fiore MC et al (2004) A multiple motives approach to tobacco dependence: the Wisconsin Inventory of Smoking Dependence Motives (WISDM-68). J Consult Clin Psychol 72:139-154

Piper ME, Bolt DM, Kim S-Y, Japuntich SJ, Smith SS, Niederdeppe J, Cannon DS, Baker TB (2008) Refining the tobacco dependence phenotype using the Wisconsin Inventory of Smoking Dependence Motives. J Abnorm Psychol 117:747-761

Roberts JS, Anton RF, Latham PK, Moak DH (1999) Factor structure and predictive validity of the obsessive compulsive drinking scale. Alcohol: Clin Exp Res 23:1484-1491

Robinson TE, Berridge KC (2003) Addiction. Ann Rev Psychol 54:25-53

Shiffman S, Waters A, Hickcox M (2004) The nicotine dependence syndrome scale: a multidimensional measure of nicotine dependence. Nicotine Tob Res 6:327-348

SRNT Subcommittee on Biochemical Verification (2002) Biochemical verification of tobacco use and cessation. Nicotine Tob Res 4:149-159

Tiffany ST (1990) A cognitive model of drug urges and drug-use behavior: role of automatic and nonautomatic processes. Psychol Rev 97:147-168

Tiffany ST, Carter BL (1998) Is craving the source of compulsive drug use? J Psychopharmacology 12:23-30

Volkow ND, Fowler JS (2000) Addiction, a disease of compulsion and drive: involvement of the orbito-frontal cortex. Cereb Cortex 10:318-325

Weiss F (2005) Neurobiology of craving, conditioned reward and relapse. Curr Opin Pharmacol 5:9-19

Ziedonis D, Hitsman B, Beckham JC, Zvolensky M, Adler L, Audrain-McGovern J, Breslau N, Brown RA, George TP, Williams J, Calhoun PS, Riley W (2008) Tobacco use and cessation in psychiatric disorders: National Institute of Mental Health report. Nicotine Tob Res 10:1691-1715 